\title{
Remote monitoring of Molten Core-Concrete Interaction experiment with Optical Fibre Sensors \& perspectives to improve nuclear safety - DISCOMS project
}

\author{
L. Maurin*, P. Ferdinand, V. Bouyer, A. Denoix, G. Jouvin, S. Rougeault, C. Journeau, \\ D. Molina, P. Tena and Y. Ouerdane \\ * CEA \\ Laurent.MAURIN@cea.fr
}

\begin{abstract}
The DISCOMS project (Distributed Sensing for Corium Monitoring and Safety) aimed at providing innovative solutions not requiring local electrical power supplies, for remote monitoring of a severe nuclear accident. The solutions are based on both long length SPNDs (Self Powered Neutron Detectors) and on distributed OFSs (Optical Fibre Sensors) capable to detect the onset of a severe accident, the corium pouring on the containment building concrete basemat, and its interaction with the concrete floor under the reactor vessel, until it spreads in the core catcher (EPR case). This paper mainly focuses on these last three detection targets achievable with distributed OFSs. It is based on the results of a Molten Core \& Concrete Interaction (MCCI) experiment, namely VULCANO, held in June 2018 with a concrete crucible equipped with overall $\sim 180 \mathrm{~m}$ long optical fibre sensing cables. This small scale experiment $(50 \mathrm{~kg}$ of prototypical corium) has demonstrated the ability of distributed OFSs to remotely provide useful data during the MCCI run: $i$ ) temperature profiles images up to about $580^{\circ} \mathrm{C}$ (single wavelength Raman DTS reflectometer) until cooling down to room temperature, ii) high spatial-resolution frequency shifts profiles, due to combined (non-selective) strain and temperature influences (Rayleigh OFDR and Brillouin reflectometers), and iii) cables lengths ablated by the corium on sections weakened by the temperature (Raman DTS, Rayleigh OFDR, telecom and photon counting reflectometers).
\end{abstract}

Index Terms-NPP (Nuclear Power Plant), nuclear safety, severe nuclear accident, corium, concrete basemat, OFS (Optical Fibre Sensor), reflectometry, distributed measurement, remote monitoring, power-supply free sensors, optical sensing cables, MCCI (Molten Core-Concrete Interaction) experiment, advices.

\section{INTRODUCTION}

$\mathrm{I}^{\mathrm{N}}$ $\mathrm{N}$ March 2011, an 9.1 magnitude earthquake struck off the north-east coast of Japan, and caused a powerful tsunami, with waves greater than $30 \mathrm{~m}$ height in some places. A wave

Acknowledgments - This work (reference number: ANR-11-RSNR-0007), was carried out within the framework of the RSNR (research on nuclear safety and radiation protection) research program launched after the FukushimaDaiichi accident, and co-funded by the French Programme d'Investissements d'Avenir (PIA) and managed by the ANR (French National Research Agency).

L. Maurin, G. Jouvin and S. Rougeault are with Institut LIST, CEA, Université Paris-Saclay, F-91120 Palaiseau, France (e-mail laurent.maurin@cea.fr). with $15 \mathrm{~m}$ height reached the Fukushima-Daiichi NPP (Nuclear Power Plant) built between $6.5 \mathrm{~m}$ and $10 \mathrm{~m}$ above the sea level.

The first consequence of this seawater submersion for the NPP was the loss of external electrical power supplies and internal means of cooling the core of the 4 nuclear reactors on the sea front. This led to a severe nuclear accident with core meltdown, ranked at level 7 on the INES scale [1].

Left with almost no information coming from the reactor pits, TEPCO was unable to monitor in real-time the accident status and its progress, whose accident management operations were also complicated by the massive destructions on the site and its surroundings.

These major drawbacks led the French national authorities to organize a few months later a parliamentary session devoted to nuclear safety in order to evaluate the mitigation strategies currently in place for Gen II and Gen III (EPR) nuclear reactors, and planned for future Gen IV [2]. This work further led to a new and dedicated research program, the RSNR [3], to stimulate and fund new R\&D topics in nuclear safety, with four main objectives: $i$ ) analyse the conditions that previously led to nuclear accidents, including the Fukushima-Daiichi event, taking into account the first conclusions of the Complementary Safety Assessments that followed [4], ii) analyse the severe accident management procedures to be considered by licensees and public authorities, for all major nuclear accidents to date, iii) analyse their impact, with regard to radioactive material releases, on human health and on the environment, and iv) enhance nuclear facilities robustness to extreme situations.

In this framework, the DISCOMS (Distributed Sensing for Corium Monitoring and Safety) project [5] aimed at providing additional ex-core remote monitoring solutions (free of local electrical power supply) able: $i$ ) to monitor the nuclear reactor during at least 60 years of normal operation, and to detect the

V. Bouyer, A. Denoix, C. Journeau, D. Molina and P. Tena are with the CEA, DEN, Cadarache, DTN, SMTA, LEAG, F-13108 Saint-Paul-lezDurance, France (e-mail: viviane.bouyer@cea.fr).

Y. Ouerdane is with Univ Lyon, UJM, CNRS, IOGS, Laboratoire Hubert Curien, UMR 5516, 18 rue Prof. B. Lauras, F-42000 Saint-Étienne, France (email: ouerdane@univ-st-etienne.fr).

P. Ferdinand, previously with Institut LIST, is now with LMP S.A., 49-51 rue du Moulin des Prés, F-75013 Paris, France (e-mail: p-ferdinandlmpsa@sfr.fr). 
onset of any nuclear accident involving the reactor core and its vessel, and ii) to monitor such accident in order to facilitate the management of the situation by the licensee and the safety authorities, by providing information in real-time about the status of the vessel breakthrough, as well as the corium pouring on the concrete basemat, its progression through the concrete floor, and the potentially failure of the third containment barrier (leading to corium spreading in the core catcher for the EPR).

These innovative means rely on passive sensors, namely long lengths (up to $6 \mathrm{~m}$ long) ex-core SPNDs (Self Powered Neutron Detectors) [6] and distributed OFSs (Optical Fibre Sensors): SPNDs would be installed in the reactor pit whereas OFSs would be located at several depths in the concrete floor, and below the core catcher (EPR). These sensors could then be monitored in real-time from a remote location (from hundreds of metres to several $\mathrm{km}$ ) where operators could work safely.

Such additional instrumentations would facilitate the situation management, thanks to decisions based also on real measurements coming from the reactor pit rather than on predictive models results taking for inputs the available measurements. This is particularly true for the concrete floor (last containment barrier), which does not benefit until now (at least for the French fleet of reactors) from any embedded sensor, but only a few thermocouples at its surface, which will be destroyed once the corium would have poured on them.

On the contrary, a few hundreds of metres of optical sensing cables embedded in the concrete floor would benefit from its radiation and thermal protections, and would withstand several additional hours during which more appropriate mitigation strategies could be implemented.

Equally important, public authorities' decision to evacuate or not the population, with regard to contamination risks, will be based on the real information coming from the NPP, otherwise provided by conservative simulation results computed during the accident. As a reminder, the global cost for the society of a severe nuclear accident which could occur in France has been estimated to $120 \mathrm{G} €$, with $11 \mathrm{G} €$ related to contaminated territories, depending on the scenario [7].

\section{MONITORING THE CONCRETE FLOOR WITH OFSS IN THE REACTOR PIT DOES MAKE SENSE}

\section{A. Modelling of radiation conditions in the reactor pit for Gen II and Gen III nuclear reactors}

Numerical simulations permitted to assess the irradiation conditions in the reactor pit versus the concrete floor depth, for both Gen II and Gen III nuclear reactors, in terms of kerma (kinetic energy released per unit mass) gamma \& fast neutrons (E $>1 \mathrm{MeV}$ ) fluence [8] [9].

For both reactors generations, results demonstrate that at any depth in the concrete floor $(>10 \mathrm{~cm})$, the kerma gamma after 60 years of normal operation is greater than effects of the first $24 \mathrm{~h}$ of a severe accident. In addition, the kerma is drastically reduced with the floor depth, due to the concrete absorption.

Thus, e.g. at $50 \mathrm{~cm}$ below the surface, the fast neutrons fluence drops from $10^{16} \mathrm{n} / \mathrm{cm}^{2}$ to $2 \times 10^{14} \mathrm{n} / \mathrm{cm}^{2}$ for Gen II, and from $10^{14} \mathrm{n} / \mathrm{cm}^{2}$ to $10^{12} \mathrm{n} / \mathrm{cm}^{2}$ for Gen III, while the kerma gamma drops from 5.5 MGy to $700 \mathrm{kGy}$ for Gen II and from $2 \mathrm{MGy}$ to $22 \mathrm{kGy}$ for Gen III after $24 \mathrm{~h}$ of a severe accident occurring after 60 years of normal operation, these values being conservative. Concrete floor shielding can therefore be advantageously used to protect optical fibres from excessive damages caused by ionizing radiations.

\section{B. Selection and qualification of radiation hardened optical fibres to be used in optical sensing cables}

In parallel, several commercially available radiations resistant singlemode optical fibres were screen-tested, first as standalone fibres, then in sensing cables in order to determine the RIA (Radiation Induced Attenuation) generated by the cable compounds (polymers) in the optical fibre core. The irradiation tests performed within the industrial gamma-irradiator POSÉİDON, and the research nuclear reactor ISIS, both located at CEA Saclay, have permitted to select rad-hard optical fibres that exhibit a maximum RIA $<50 \mathrm{~dB} / \mathrm{km}$ at both $1310 \mathrm{~nm}$ and $1550 \mathrm{~nm}$ operating wavelengths, for cumulated gamma-dose close to 2 MGy [10].

It has also been proved that under irradiations, the cable polymer compounds release molecular hydrogen $\mathrm{H}_{2}$, which migrates towards the optical fibre core, and is finally responsible for significant additional RIA, without highlighting any tendency to saturation. One solution, qualified during this project, is to use an optical fibre with a protective carbon layer at its surface, thus acting as a barrier against hydrogen [10].

\section{OFSs in the reactor pit to remotely monitor the corium and its progression throughout the concrete floor}

We allocate a maximum optical budget of $5 \mathrm{~dB}$ to the monitored parts, based on performances of today's optical fibre sensing systems. Combined with experimental RIA results versus cumulated dose, the modelling assesses that it makes sense to embed sections of $100 \mathrm{~m}$ of optical fibre(s) sensing cables at several depths in the concrete floor reactor pit. Minimum embedment depth of $30 \mathrm{~cm}$ and $5 \mathrm{~cm}$ below the top surface, for Gen II and Gen III respectively, will ensure correct measurements of cable lengths, strains \& temperature profiles, as well as temperature changes from a reference trace [10].

The distributed sensing measurement principles rely on the analysis of the backscattered light by dedicated reflectometers as described in Table I. The useful information provided are profiles with typically $50 \mathrm{~cm}$ to $1 \mathrm{~m}$ raw spatial sampling over several kilometres for both Raman DTS and Brillouin instruments, with a measurement frequency ranging from one to several minutes (depending on the setting parameters). The Rayleigh OFDR technique provides better spatial sampling measurements and rates, typically from one to several centimetres, over much shorter sensor lengths (Table I).

Cable lengths are provided by reflectometers (telecom or photon counting OTDRs) through the detection of the Fresnel reflexion peak at the fibre tip, even if some distributed sensing reflectometers can also provide this information.

The main advantage of photon counting over traditional OTDR is the shorter raw spatial sampling: typically, $1 \mathrm{~cm}$ versus $1 \mathrm{~m}$. For both techniques, measurement ranges exceed 
$20 \mathrm{~km}$, with $\sim 1$ minute measurement time (depending on both setting parameters and the expected signal to noise ratio).

These five C-band singlemode measurement techniques can therefore be operated far away from the reactor pit (where operators can work safely), on the condition that the total RIA does not exceed the optical budgets. Instruments can be swapped from one cable to another one in case of failure.

\section{OPTICAL FIBRE SENSING CABLE TESTS AND SELECTION FOR THE VULCANO EXPERIMENT}

Three different kinds of optical fibre sensing cables, devoted to strain sensing, temperature sensing and security, were supplied on the market (Table II). Their compliance with EDF PMUC standard [11] was required in the call for tenders.

They were first qualified in temperature between $4^{\circ} \mathrm{C}$ and $85^{\circ} \mathrm{C}$ to reflect normal operation, then at higher temperatures (up to $750^{\circ} \mathrm{C}$ ) to characterize their sustainability to corium vicinity during a severe nuclear accident. The strain cables were tested in elongation to characterize their strain transduction.

\section{A. Tests between $4^{\circ} \mathrm{C}$ and $85^{\circ} \mathrm{C}-$ Normal operation scenario}

For each cable, $10 \mathrm{~m}$-sections were spliced together, then tested in a climatic chamber (between $4^{\circ} \mathrm{C}$ and $85^{\circ} \mathrm{C}$ ) while their Rayleigh frequency shifts profiles were recorded for each temperature step. It could be noticed that both temperature and safety cables exhibited irregular profiles, and also more pronounced side effects at their ends, in comparison with strain sensing cables (Fig. 1). This is due to a higher temperature sensitivity in the latter case, the optical fibre being glued along its length in a small diameter metallic tubing (Fig. 6).

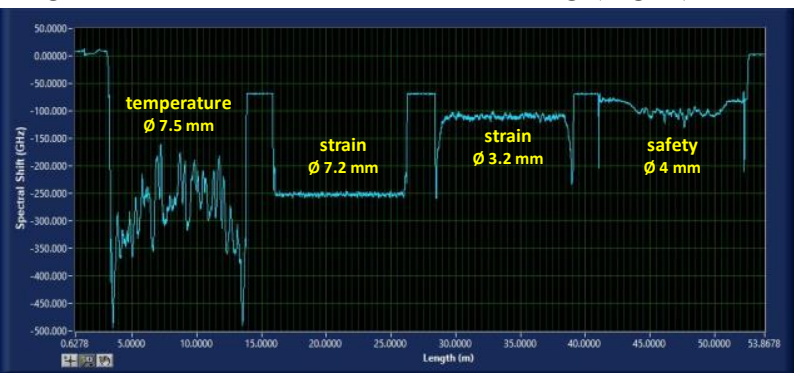

Fig. 1. Typical Rayleigh OFDR frequency shifts profiles between $4^{\circ} \mathrm{C}$ and $58^{\circ} \mathrm{C}$ for the 4 optical sensing cables parts spliced together.

Ø $7.2 \mathrm{~mm}$-diameter strain and temperature sensing cables provide the highest temperature sensitivities due, for the latter, to a significant friction between the fibre in its plastic tubing with the gel (Table II). But the temperature cable is not the optimal choice, even if the optical fibre thermal expansion is expected to be driven by the concrete if cables are embedded.

Therefore, with more homogenous profiles at constant temperature, the $\varnothing 7.2 \mathrm{~mm}$ strain sensing cable is the better choice for distributed temperature sensing.

\section{B. Tests up to $750^{\circ} \mathrm{C}$ - Severe accident scenario}

The cable sustainability in corium vicinity is of major importance for the severe accident monitoring in order to get measurements coming from the reactor pit as long as possible. It can also be noticed that the security cable, devoted to the fire detection market, has been especially designed to sustain $750^{\circ} \mathrm{C}$
TABLE I

OPTICAL FIBRE DISTRIBUTED SENSING DURING VULCANO EXPERIMENT

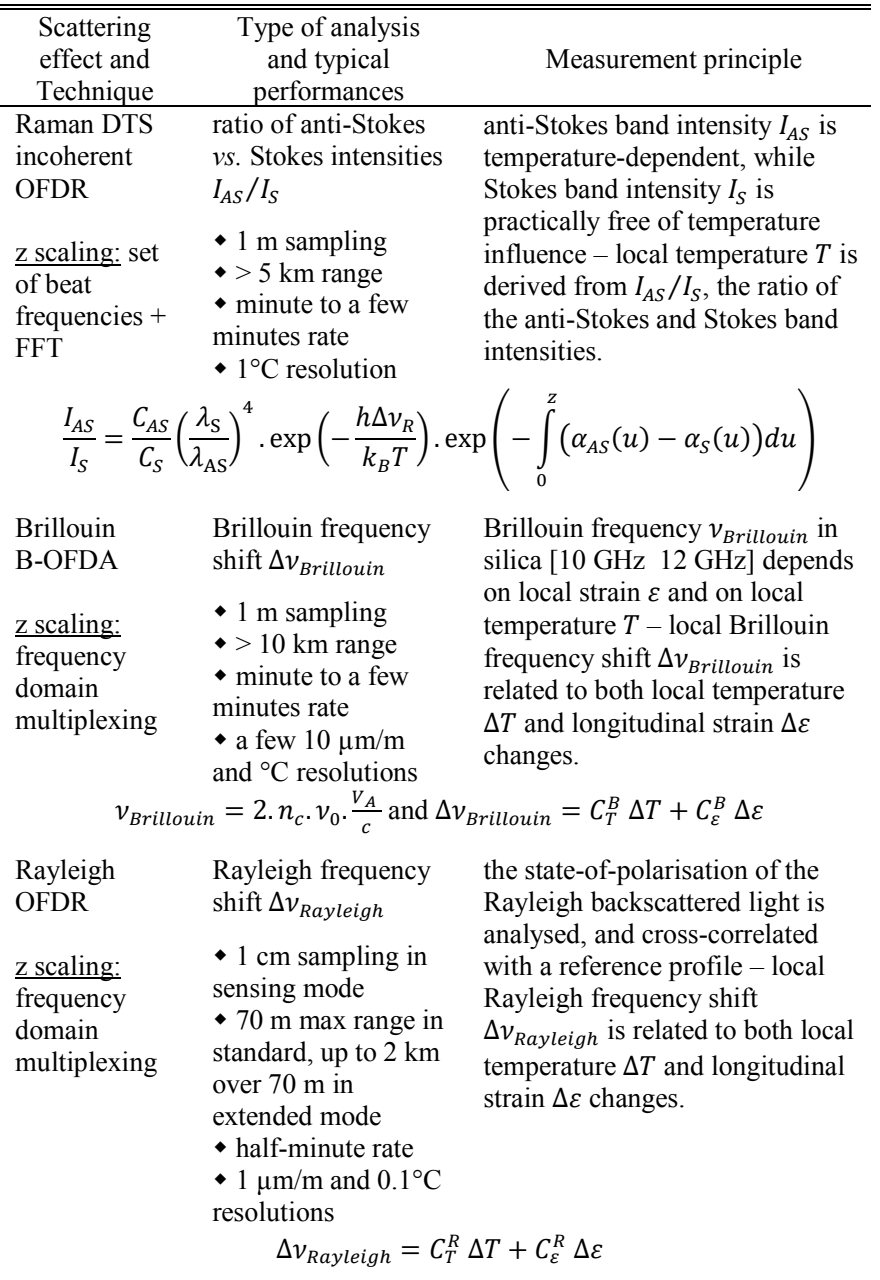

Raman DTS: $k_{B}$ is the Boltzmann's constant, $h$ the Planck's constant, $C_{S(A S)}$ are defined by the Raman cross-section for the Stokes (anti-Stokes) lines and by the band-pass filters used to select them, $\Delta v_{R}$ is the Raman frequency shift (13.2 THz for silica), $T$ is the temperature in Kelvin, $\alpha_{S(A S)}$ are the Stokes (anti-Stokes) attenuation coefficients including all fibre losses. $\lambda_{S}-\lambda_{0}=\lambda_{0}-\lambda_{A S} \cong 100 \mathrm{~nm}$ with probe wavelength $\lambda_{0}=1550 \mathrm{~nm}$.

Brillouin: $V_{A}$ is the speed of sound in silica $(5.96 \mathrm{~km} / \mathrm{s}), c$ the speed of light in vacuum, $n_{c} \cong 1.47$ the core refractive index, $C_{T}^{B} \cong 950 \mathrm{kHz} /{ }^{\circ} \mathrm{C}$ and $C_{\varepsilon}^{B} \cong 50.55 \mathrm{kHz} /(\mu \mathrm{m} / \mathrm{m})$ with probe wavelength $\lambda_{0}=1550 \mathrm{~nm}$.

Rayleigh OFDR: $C_{T}^{R} \cong-1.25 \mathrm{GHz} /{ }^{\circ} \mathrm{C}$ and $C_{\varepsilon}^{R} \cong-0.150 \mathrm{GHz} /(\mu \mathrm{m} / \mathrm{m})$ with probe wavelength $\lambda_{0}=1550 \mathrm{~nm}$.

during at least 90 minutes according to IEC 60331-25 standard in terms of optical waveguide continuity [12]. However, unlike the standard test which must be performed with a flame, the cables were placed in a metallic pipe, and the pipe itself in a tubular oven. The temperature profile along the tube was controlled thanks to 4 type-K thermocouples (Fig. 2), and it could be assumed that at least $40 \mathrm{~cm}$ of cable length were
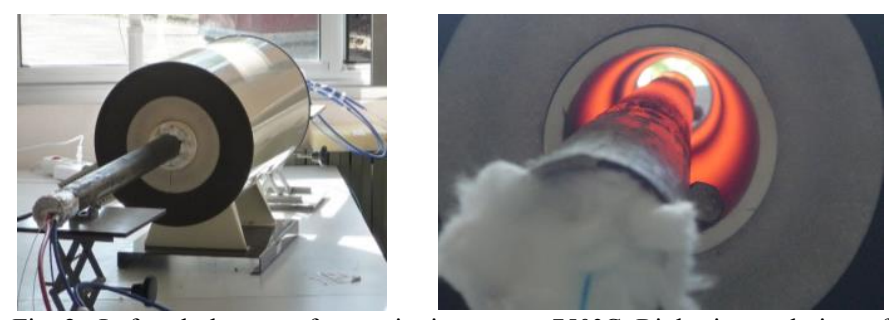

Fig. 2. Left: tubular oven for continuity tests at $750^{\circ} \mathrm{C}$. Right: internal view of the tubular oven at $750^{\circ} \mathrm{C}$ with the pipe and the sensing cable under test. 
systematically heated over the $750^{\circ} \mathrm{C}$ target during the tests.

Results are summarized in Table II. The optical continuity was controlled with a telecom OTDR.

As expected, the security cable passed the tests, even up to $2 \mathrm{~h} 30 \mathrm{~min}$ at $750^{\circ} \mathrm{C}$, but its sheath had burnt, and only the tight buffered parts were partially observable (Fig. 3 ). Indeed, the cable, nor the fibre, did not exhibit any significant residual mechanical strength after this test.

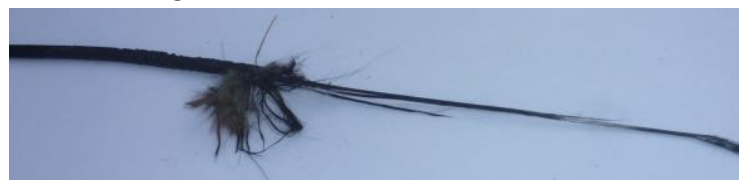

Fig. 3. Typical aspect of the security cable after more than two hours at $750^{\circ} \mathrm{C}$

The most surprising result concerned the temperature cable which also passed the test, although it was not specified for such a purpose by its manufacturer. Its polymer sheath has disappeared in fumes during the test, and only the very fragile bare optical fibre (without its polymer coating) remained. Nevertheless, this result should be considered with caution: in case of an embedded cable, the optical fibre would have probably been broken due to the mechanical stresses driven by the concrete thermal expansion.

The last interesting result is the early break of the optical fibre in the two strain sensing cables, which was systematically observed between $400^{\circ} \mathrm{C}$ and $450^{\circ} \mathrm{C}$ for both cables. This can be explained by the conversion of their thermal expansion $\alpha_{\text {fibre }} \Delta T$ into mechanical strain $\Delta \varepsilon_{\text {fibre }}$ according to:

$$
\Delta \varepsilon_{\text {fibre }} \cong\left(\alpha_{\text {cable }}-\alpha_{\text {fibre }}\right) \times \Delta T
$$

With $\alpha_{\text {cable }}-\alpha_{\text {fibre }} \cong 50 \times 10^{-6}{ }^{\circ} \mathrm{C}^{-1}$, it leads to an equivalent mechanical elongation of the optical fibre greater than $2 \%$ (i.e.: twice the $1 \%$ standard telecom screen-test level). As expected, the polymer cable sheath has burned, and only the central metallic tubing remained (Fig. 4).

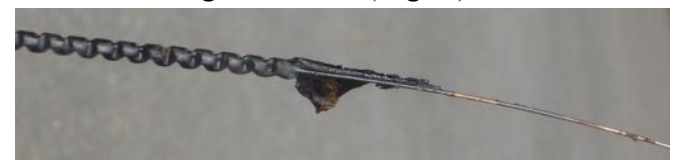

Fig. 4. Typical aspect of the $\varnothing 3.2 \mathrm{~mm}$ strain sensing cable after $2 \mathrm{~h}$ at $750^{\circ} \mathrm{C}$.

\section{Mechanical tests on strain sensing cables}

Only the two strain cables have been tested to characterize their ability to transduce the mechanical strains applied on their surface to the embedded optical fibre. Such cables could be used to detect corium pouring on the concrete floor below the vessel, through a progressive strain increase as far as the corresponding stresses rise, taking into account for the EPR an overall mass close to $300 \mathrm{t}$ applied on $\sim 30 \mathrm{~m}^{2}$ of surface, i.e.: an equivalent stress close to $10^{5} \mathrm{~Pa}$ ( 1 bar hydrostatic pressure equivalent), with up to 20 bar additional hydrostatic pressure in case of hydrogen release (before the reactor building breaks).

The experimental set-up consisted of one cable section attached between two translation stages. Step by step translations were applied, which resulted in homogeneous elongations applied to the cable (Fig. 5, left).
TABLE II

OPTICAL FIBRE SENSING CABLES SELECTED FOR CORIUM MONITORING

\begin{tabular}{|c|c|c|}
\hline Strain sensing & Temperature sensing & Security \\
\hline $\begin{array}{l}\text { - } 1 \text { optical fibre glued } \\
\text { into hermetic metallic }\end{array}$ & $\begin{array}{l}\text { - up to } 12 \text { optical } \\
\text { fibres in a plastic }\end{array}$ & $\begin{array}{l}\text { - } 2 \text { tight buffered } \\
\text { optical fibres }\end{array}$ \\
\hline tubing & loose tube filled & no metallic \\
\hline - specific external & with gel & reinforcement \\
\hline structure for better & - no metallic & - compliant with IEC \\
\hline $\begin{array}{l}\text { anchorage in concrete } \\
\text { metallic reinforcement } \\
\text { for the } \varnothing 7.2 \mathrm{~mm} \text { cable }\end{array}$ & reinforcement & $\begin{array}{l}60331-25 \text { for circuit } \\
\text { integrity at } 750^{\circ} \mathrm{C}\end{array}$ \\
\hline $\begin{array}{l}\text { - provided in Ø } 3.2 \mathrm{~mm} \\
\text { and } \varnothing 7.2 \mathrm{~mm}\end{array}$ & $\begin{array}{l}\bullet \text { provided in } \\
\varnothing 7.5 \mathrm{~mm}\end{array}$ & - provided in $\varnothing 4 \mathrm{~mm}$ \\
\hline
\end{tabular}

TEMPERATURE SENSITIVITY BETWEEN $4^{\circ} \mathrm{C}$ AND $85^{\circ} \mathrm{C}$ RAYLEIGH OFDR FREQUENCY SHIFTS MEASUREMENTS

\begin{tabular}{|c|c|c|}
\hline $\begin{array}{l}-1.90 \mathrm{GHz} /{ }^{\circ} \mathrm{C} \varnothing 3.2 \mathrm{~mm} \\
-4.54 \mathrm{GHz} /{ }^{\circ} \mathrm{C} \varnothing 7.2 \mathrm{~mm}\end{array}$ & $-4.25 \mathrm{GHz} /{ }^{\circ} \mathrm{C}$ & $-1.82 \mathrm{GHz} /{ }^{\circ} \mathrm{C}$ \\
\hline \multicolumn{3}{|c|}{$\begin{array}{l}\text { OPTICAL FIBRE CONTINUITY DURING } 90 \mathrm{~min} \text { AT } 750^{\circ} \mathrm{C} \\
\text { TESTS PERFORMED IN A TUBULAR OVEN, CABLE IN A PIPE }\end{array}$} \\
\hline $\begin{array}{l}\text { optical fibre } \\
\text { systematically broken } \\
\text { between } 400^{\circ} \mathrm{C} \& 450^{\circ} \mathrm{C}\end{array}$ & $\begin{array}{l}\text { pass } \\
\text { (but not a product } \\
\text { specification) }\end{array}$ & pass \\
\hline
\end{tabular}

Strain profiles were measured with Rayleigh OFDR technique and were quite homogenous, even if discrepancies appeared, which also might be the result of the winding process on the delivery strands (Fig. 5, right).
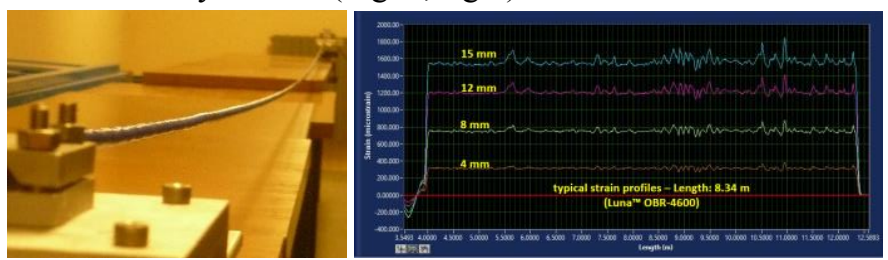

Fig. 5. Experimental set-up for strain cable characterization. Left: cable horizontally pulled between two translation stages. Right: strain profiles recorded for several translation steps (e.g.: $4 \mathrm{~mm}, 8 \mathrm{~mm}, 12 \mathrm{~mm}$ and $15 \mathrm{~mm}$ ).

Several strain cycles were performed, and the average strain for the tested sections recorded versus the translation steps. The analysis led to typical hysteresis values smaller than $15 \mu \mathrm{m} / \mathrm{m}$ for $1600 \mu \mathrm{m} / \mathrm{m}$ strain range, i.e.: less than $1 \%$ full scale (Fig. 6 , left), which is an excellent result for such a complex structure made of different materials layers.
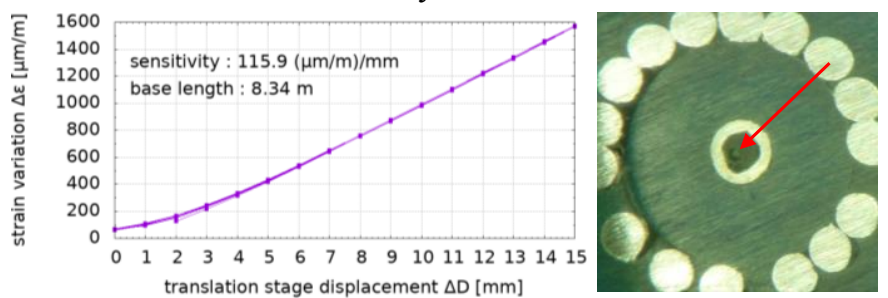

Fig. 6. Left: average strain versus displacements (cycles). Right: strain sensing cable section with the optical fibre glued along its length in the central tubing.

An explanation is the strain transduction mechanism, based on the shear $\Delta \gamma$ of a thin glue layer in the cable central tubing, this transduction efficiency being: $i$ ) inversely proportional to its thickness $e$ (estimated smaller than $400 \mu \mathrm{m}$, Fig. 6, right), and ii) proportional to its stiffness characterized by its Young's modulus $E$. Assuming that the optical fibre diameter is small ${ }^{1}$ in comparison with the central tubing inner diameter:

$\Delta \tau \cong \frac{E}{2(1+v)} \Delta \gamma$ with: $\Delta \gamma \cong \frac{\delta d}{e} \Rightarrow \delta d \cong \frac{2(1+v) e}{E} \Delta \tau$ 
with $\Delta \tau$ the shear stress (proportional to the applied pulling force), $v$ the glue Poisson ratio and $\delta d$ the relative optical fibre displacement in the tubing. If $\Delta D$ is the cable translation stage displacement and $D$ the length of the section under test, the strain hysteresis can then be estimated of the same order of magnitude than $\delta d / \Delta D \cong \frac{2(1+v) e}{E \Delta D} \Delta \tau$.

This explanation for strain is compliant with the early fibre break stated for temperatures starting from $400^{\circ} \mathrm{C}$, since the differential thermal expansion between the optical fibre and the cable is quasi-exclusively converted into mechanical strain with an amplification factor roughly equal to $\alpha_{\text {cable }} / \alpha_{\text {fibre }} \gg 1$.

\section{Cables candidates for corium monitoring}

Therefore, the most interesting sensing cables $^{2}$ for corium monitoring are: 1) the strain sensing cables in a safety role, for their earlier corium vicinity detection capability (from $400^{\circ} \mathrm{C}$ ) likewise their ability to detect strain profiles resulting both from corium pouring on the floor and hydrostatic pressure increase in the reactor pit, and 2) the safety cable, for its ability to sustain $750^{\circ} \mathrm{C}$ during at least 90 minutes (Table II).

With a typical temperature gradient equal to $250^{\circ} \mathrm{C} / \mathrm{cm}$ in the concrete, and a temperature front progression speed typically about $5 \mathrm{~cm} / \mathrm{h}$ after 12 hours of a severe accident, it would take $\sim 17$ minutes to heat from $400^{\circ} \mathrm{C}$ up to $750^{\circ} \mathrm{C}$. This would be an additional detection delay during which safety cables could still provide measurements in comparison with strain cables.

\section{THE VULCANO SMALL SCALE FINAL MCCI EXPERIMENT}

The VULCANO experiment has consisted in obtaining a depleted $\mathrm{UO}_{2}$ prototypical corium pool into a concrete crucible, and monitoring the resulting concrete ablation. The test section (Fig. 7) is 2D cylindrical (Ø $250 \mathrm{~mm}$ inner and Ø $500 \mathrm{~mm}$ outer diameters), with $300 \mathrm{~mm}$ inner and $650 \mathrm{~mm}$ outer heights.
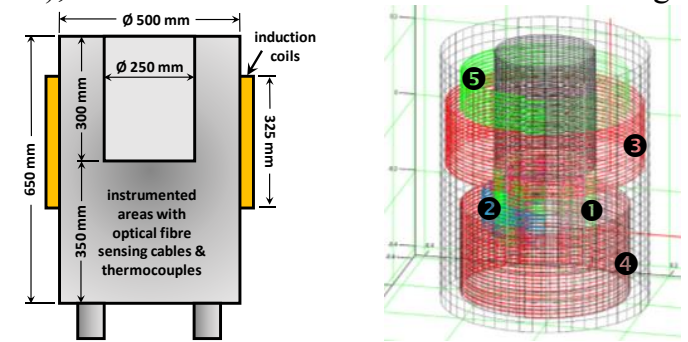

Fig. 7. The VULCANO concrete crucible. Left: crucible dimensions. Right: position of the 5 sensing cables wounded around and below the melted pool.

It is equipped with a hundred of type-K, plus 6 type-C thermocouples, located on 6 azimuths. Type-C thermocouples enable temperature measurements at the bottom of the melted pool, whereas the main role of type-K thermocouples (identified as "failure-thermocouples") is devoted to track the concrete ablation front; their measurements also provide information about temperature distribution in the concrete.

Five twin optical fibres sensing cables are incorporated in the

\footnotetext{
${ }^{2}$ For embedded cables, these results are not fully representative, because they do not take into account the mechanical stresses (consequence of differential thermal expansions) applied by the concrete, nor the confinement of the fumes released by the cables polymer compounds (which might also induce some additional attenuation in the optical fibres).
}

TABLE III

CABLES POSITION \& DEDICATED MEASUREMENT TECHNIQUES

\begin{tabular}{|c|c|c|}
\hline cable & $\begin{array}{l}\text { cable position } \\
\& \text { sensing length }\end{array}$ & $\begin{array}{l}\text { optical measurement technique } \\
\& \text { sensing parameters }\end{array}$ \\
\hline (1) & $\begin{array}{l}\text { below melted pool } \\
1 \text { turn } \sim 55 \mathrm{~cm} \\
19 \mathrm{~m} \mathrm{sensing} \mathrm{length}\end{array}$ & $\begin{array}{l}\text { photon counting OTDR / cable length } \\
\text { telecom OTDR / cable length }\end{array}$ \\
\hline 2 & $\begin{array}{l}\text { below melted pool } \\
1 \text { turn } \sim 75 \mathrm{~cm}\end{array}$ & $\begin{array}{l}\text { Rayleigh OFDR / \{strain \& temperature }\} \& \\
\text { cable length }\end{array}$ \\
\hline 4 & $\begin{array}{l}25 \mathrm{~m} \text { sensing length } \\
\text { below melted pool }\end{array}$ & $\begin{array}{l}\text { Raman DTS / \{temperature\} \& cable length } \\
\text { Brillouin B-OFDA / \{strain \& temperature\} }\end{array}$ \\
\hline 5 & $\begin{array}{l}1 \text { turn } \sim 95 \mathrm{~cm} \\
22 \mathrm{~m} \text { sensing length } \\
\text { around melted pool } \\
1 \text { turn } \sim 125 \mathrm{~cm} \\
25 \mathrm{~m} \text { sensing length }\end{array}$ & Raman DTS / \{temperature\} \& cable length \\
\hline
\end{tabular}

Optical fibres in cable $\mathbf{3}$ were both not exploitable for optical sensing due to elevated optical losses after concrete casting.

Sensing lengths do not take into account additional lengths incorporated in the concrete crucible to connect to the remote instruments.

concrete test section, for an overall length close to $180 \mathrm{~m}$. Both thermocouples and optical fibre sensing cables were attached on nylon strings to lock their position before concrete casting.

\section{A. Optical fibre sensing cables arrangement in the crucible}

To overcome spatial sampling issues with a concrete crucible external circumference close to $1.5 \mathrm{~m}$, each cable, around and below the pool, was arranged to make 2 turns at the same height to improve the vertical depth sampling (Table III), and the distance between two pairs of turns was set to $1 \mathrm{~cm}$. At least 2 measurements at each depth could have been achieved for both Brillouin and Raman DTS instruments.

The security cable was selected for 3 main reasons: i) its small $\varnothing 4 \mathrm{~mm}$ diameter to reduce risks of cracks propagation which could have led to a crucible break, ii) its compatibility with Eddy currents generated by the induction coils, and iii) its ability to sustain high temperatures to provide measurements as long as possible. The optical fibres were traditional (i.e.: non rad-hard) bend insensitive ITU-T G.657-type ${ }^{3}$.

\section{B. Remote monitoring principle during experiment}

The five optical measurement systems depicted in Tables I \& III were located $20 \mathrm{~m}$ away from the instrumented crucible, and the control station with all the staff in a separate building at $\sim 100 \mathrm{~m}$ distance. These instruments were connected to a Local Area Network and synchronized with the same network clock. All the measurement files were stored on a network share, with a periodical replication on a remote mirror for security reasons: they could be retrieved in real-time for specific interfaces, without interfering with the optical measurement loops (Fig. 8).

\footnotetext{
${ }^{3}$ It has already been assessed during this project that the best commercial radiation resistant fibres, embedded into their sensing cables, can sustain the expected radiation levels, without exceeding the maximum allowed RIA [10].
} 


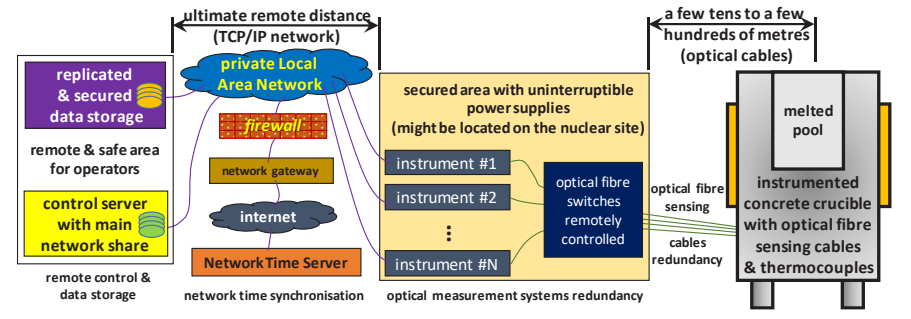

Fig. 8. Remote monitoring principle retained for the VULCANO experiment in DISCOMS project. Redundancy is achieved by switching instruments and/or cables thanks to several optical switches remotely controlled.

\section{The VULCANO experiment held on the $26^{\text {th }}$ of June, 2018}

The $50 \mathrm{~kg}$ corium pool was obtained by thermite reaction (a self-propagating strongly exothermic high temperature synthesis method) directly into the concrete crucible (Fig. 9).
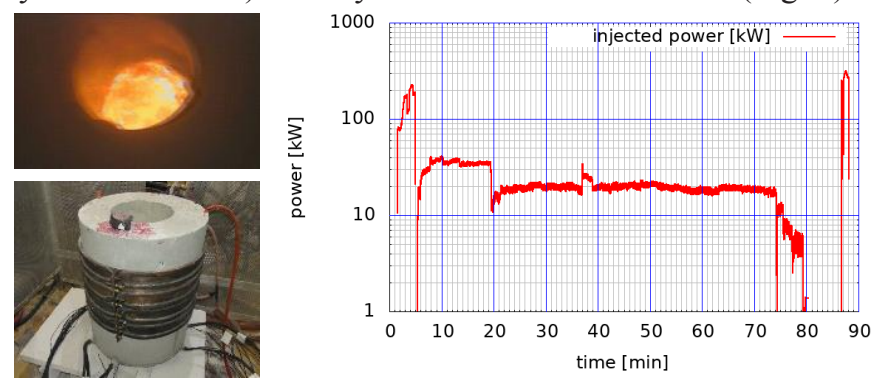

Fig. 9. Left top: corium pool a few seconds after the thermite reaction ignition. Left bottom: concrete crucible with its induction coils. Right: injected power during the experiment.

Induction coils surrounding the test section provided sustained heating power in the corium by Eddy currents into the melted pool. During this experiment, MCCI was carried out during $\sim 90$ minutes with an injected power varying from $\sim 200 \mathrm{~kW}$ down to $\sim 25 \mathrm{~kW}$. Optical measurements were performed during the entire duration of this experiment, up to complete cooling at room temperature $\sim 23$ hours later.

\section{CORIUM MONITORING RESULTS AND INTERPRETATION}

\section{A. Backscattered signal, cable length \& damage process}

The first analysis was performed on cable lengths given by the Fresnel's reflexion at the fibre tip. It highlighted an ablation process in 2 steps: $i$ ) first of all, strong damages due to high temperatures, visible on backscattered traces by increased optical losses, and then ii) the optical fibre break, a few minutes later, somewhere along the weakened section, leading to typically several metres of optical fibre loss (Fig. 10).
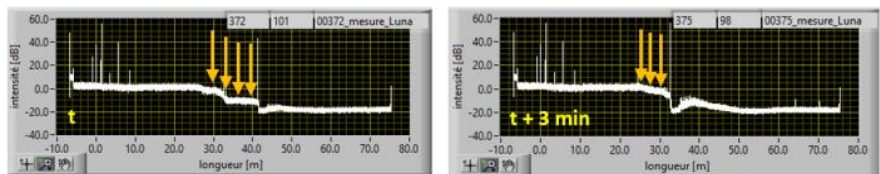

Fig. 10. Optical sensing cable damage in corium vicinity indicated by high optical losses, highlighted by arrows (Rayleigh OFDR).

This process may also lead to damages at several locations, and to a competition between Fresnel's reflexion peaks, which drastically complicates cable length detection (Fig. 11).

The ablation progress, based on the Fresnel's reflexion peak location as reference, continued during several hours even after the induction had stopped, thus probably indicating the effect of differential thermal strains during concrete cooling (Fig. 12).

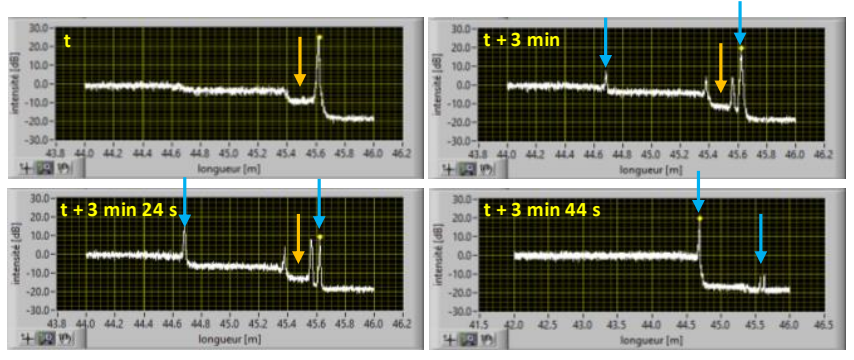

Fig. 11. Competition between several Fresnel's peaks (blue arrows) and optical fibre and cable damage process in corium vicinity (Rayleigh OFDR).

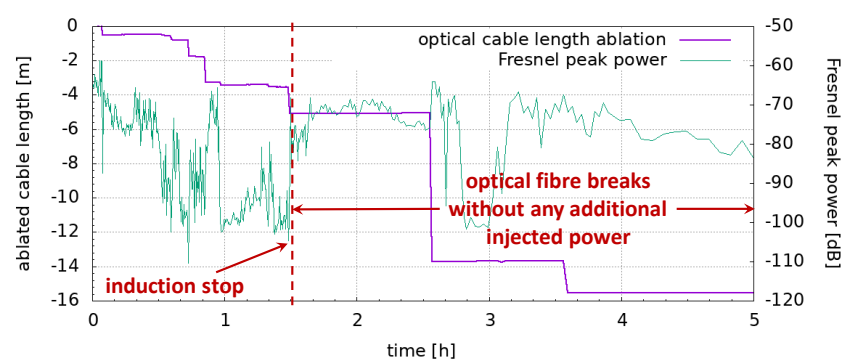

Fig. 12. Equivalent cable length ablation versus time. Optical fibre breaks continued several hours after injected power had stopped (Rayleigh OFDR).

Considering the optical fibre length as an image of the MCCI, ablated depths were compliant with thermocouples indications (Fig. 13).

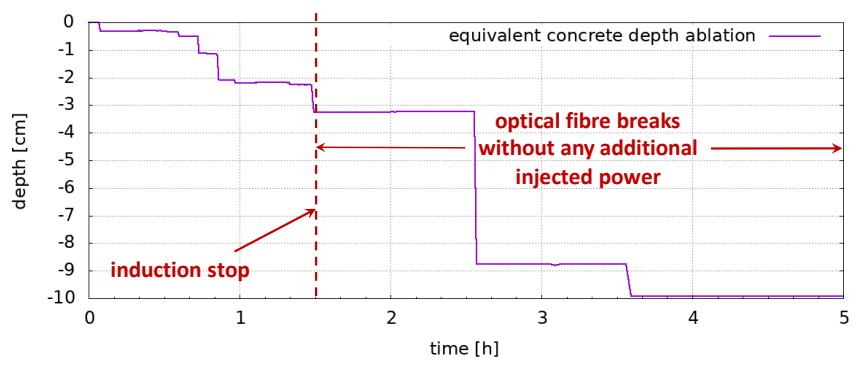

Fig. 13. Equivalent concrete depth interaction versus time (Rayleigh ODFR).

Telecom OTDR measurements analysis led to similar results, except for the Fresnel's reflexion peaks which were sometimes difficult to track, requiring manual detections. More reliable detections would require specific algorithms implementation, resilient enough to sustain high optical losses, and taking into account events history. It can also be noticed that most of the time, the Fresnel's peak power was greater at $1310 \mathrm{~nm}$ in comparison with measurements at $1550 \mathrm{~nm}$ (Fig. 14).

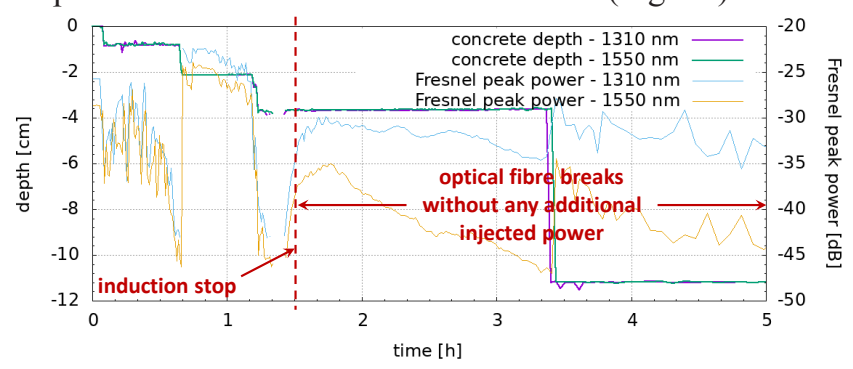

Fig. 14. Equivalent concrete depth interaction versus time (telecom OTDR, measurements at $1310 \mathrm{~nm}$ and $1550 \mathrm{~nm}$ ).

But the worst case was encountered with photon counting OTDR, whose signal disappeared during several tens of minutes, making this technique not suitable for reliable corium detection during MCCI, but rather during cooling (Fig. 15). 


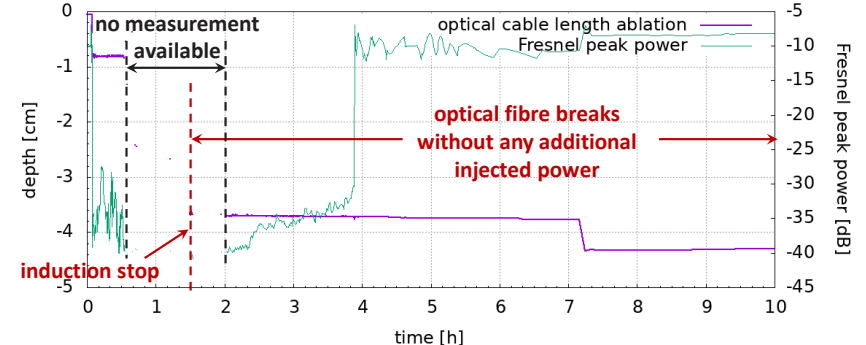

Fig. 15. Equivalent concrete depth interaction versus time (photon counting OTDR). Fresnel's peak disappeared during $90 \mathrm{~min}$ in corium vicinity.

Nevertheless, for the same sensing cable, comparison between telecom and photon counting OTDRs measurements showed the same results when measurements became again available ( 2 hours after induction stop). During cooling, some slight noticeable differences might be explained by differential thermal expansions affecting differently the 2 fibres (Fig. 16).

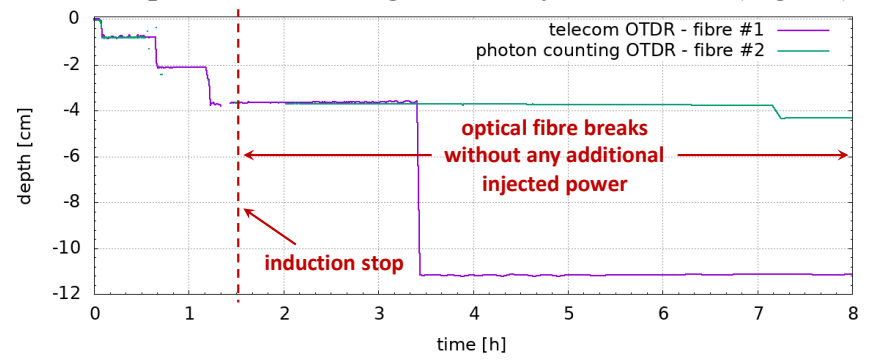

Fig. 16. Measurements comparison between telecom OTDR and photon counting OTDR (two different optical fibres in the same sensing cable).

\section{B. Sensing - Rayleigh OFDR, Brillouin and Raman DTS}

Rayleigh frequency shifts were computed by summation of frequency shifts steps $\Delta v_{R \rightarrow i+1}$ to avoid post-processing artefacts, but measurement traces still appeared noisy (Fig. 17).

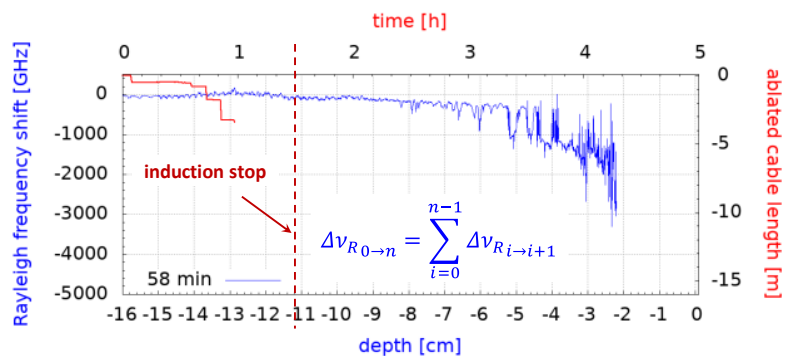

Fig. 17. Blue: typical Rayleigh frequency shift profile versus concrete depth after $58 \mathrm{~min}$ of interaction with corium. Red: ablated cable length.

Estimated temperatures, according to sensitivity given in Table I, have reached values greater than $1500^{\circ} \mathrm{C}$, in the hypothesis of negligible mechanical effects.

Brillouin measurements gave realistic combined (nonselective) temperature and strain gradients indications in the concrete. However, in order to avoid to open the measurement loop (Brillouin B-OFDA sensing is stimulated), the sensing cable was located at $6 \mathrm{~cm}$ from the pool: the temperature gradient could be estimated about $25^{\circ} \mathrm{C} / \mathrm{cm}$ (assuming negligible mechanical effects), which is one magnitude order less than expected while in close contact with corium (Fig. 18).

\footnotetext{
${ }^{4}$ Higher temperatures were not achievable with this single-wavelength Raman DTS instrument, unable to compensate efficiently significant differential attenuations between Stokes and anti-Stokes lines: a dual-
}

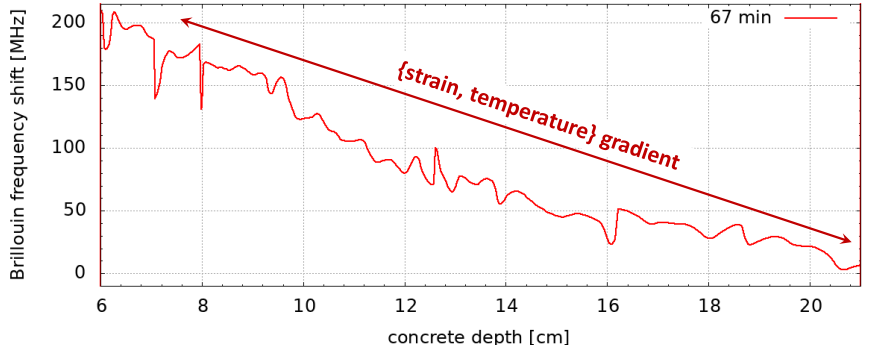

Fig. 18. Combined \{strain \& temperature\} profile expressed in Brillouin frequency shift versus concrete depth, after $67 \mathrm{~min}$ of MCCI.

Raman DTS also provided realistic short term temperature profiles up to $\sim 580^{\circ} \mathrm{C}$ in concrete ${ }^{4}$. Temperature gradients $|\nabla T|$ in corium vicinity were estimated close to $200^{\circ} \mathrm{C} / \mathrm{cm}$, and close to $25^{\circ} \mathrm{C} / \mathrm{cm}, 6 \mathrm{~cm}$ deeper in concrete, compliant with Brillouin results (Fig. 19).

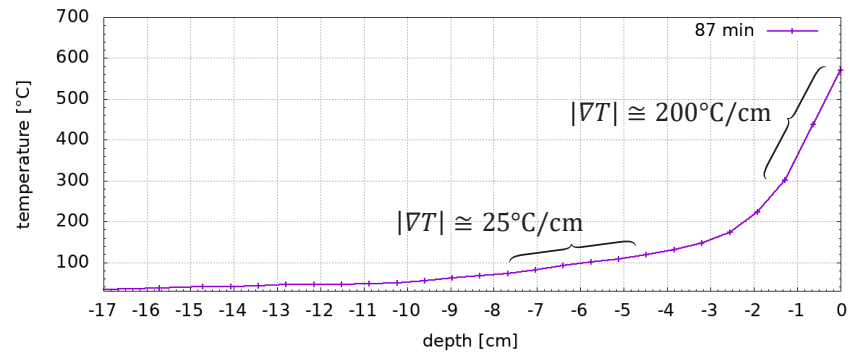

Fig. 19. Temperature profile versus concrete depth after $87 \mathrm{~min}$ of MCC (Raman DTS).

Raman DTS measurements during cooling exhibited profiles also compliant with expected results, with ambient temperature reached $\sim 23$ hours later (Fig. 20).

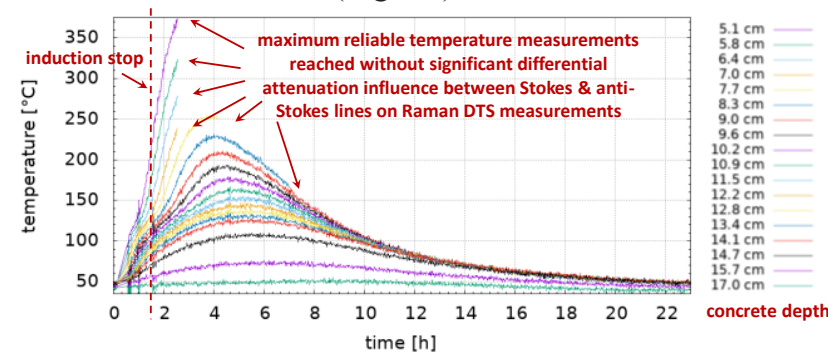

Fig. 20. Temperature versus elapsed time at several depths (Raman DTS).

Optical and thermocouples measurements exhibit the same tendencies. More accurate comparisons were not possible since optical measurements are integrated over $\sim 1 \mathrm{~m}$ (Fig. 21).
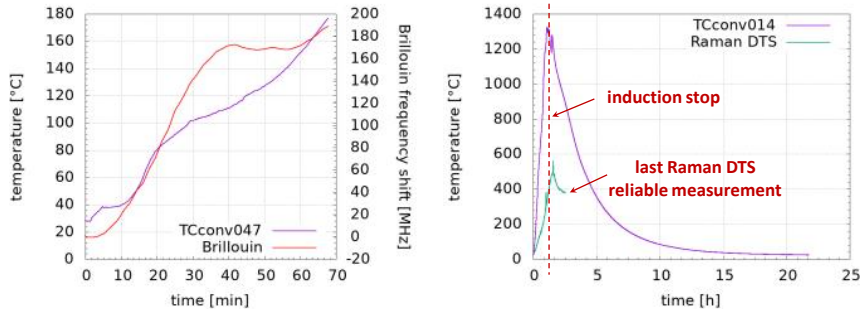

Fig. 21. Left: Brillouin frequency shift compared with thermocouple (depth: $70 \mathrm{~mm}$ ). Right: Raman DTS temperature compared with thermocouple (depth: $25 \mathrm{~mm})$.

However, with the hypothesis of the sole effect of temperature on the Brillouin frequency shift, measurements

wavelengths Raman DTS instrument is mandatory for temperatures greater than $500^{\circ} \mathrm{C}[13]$. 
appear to be compatible with thermocouple data (Fig. 21, left). Strong discrepancies with Raman DTS are probably due to its measurement principle, not efficient enough for differential Stokes \& anti-Stokes attenuations compensation (Fig 21, right).

Post-mortem concrete analysis also showed the remaining optical sensing cables, apparently not damaged, only a few centimetres away from the melted pool (Fig. 22).
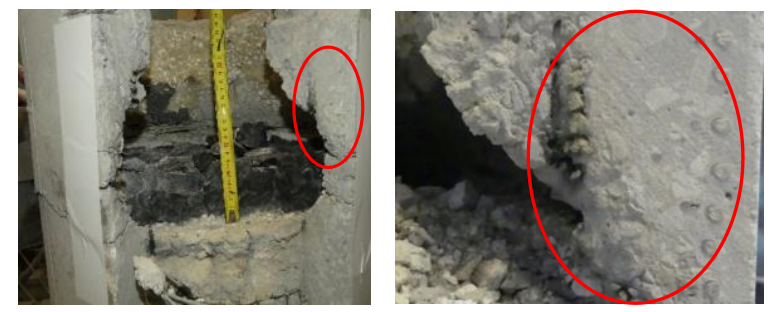

Fig. 22. Post-mortem analysis with remaining sensing cables apparently intact.

\section{CONCLUSION AND PERSPECTIVES}

The DISCOMS project is clearly a credible answer to the lack of information coming from the reactor pit in case of a severe accident. Its final demonstration, carried out during a MCCI test on the VULCANO facility of the CEA Cadarache PLINIUS Platform, the $26^{\text {th }}$ of June, 2018, has demonstrated the potential of singlemode Distributed Optical Fibre Sensing to provide valuable information (cable lengths, temperature and strain profiles) which could be advantageously taken into account by operators to monitor severe nuclear accidents from a remote and safe location, and improve nuclear safety.

DISCOMS consortium therefore recommends:

1) Radiation hardened Raman DTS technique to provide reliable temperature measurements up to $700^{\circ} \mathrm{C}$ [13],

2) Spontaneous Brillouin technique to provide strain and temperature shifts profiles up to $1000^{\circ} \mathrm{C}$, even in case of optical fibre break, but also for its resilience to ionizing radiations [14]. Instrumentations capable to dissociate strains from temperature could also be preferred if this is of crucial importance [15].

Additional telecom OTDR can be used for cable (optical fibre) length detection, along with reliable Fresnel's reflexion peak detection algorithms (resilient to optical losses). Strain sensing and security cables, with embedded radiation resistant optical fibres with a protective carbon coating layer [10], should be used for respectively early detection of corium vicinity (from $400^{\circ} \mathrm{C}$ in a safety role) and monitoring up to at least $750^{\circ} \mathrm{C}$.

Such corium remote monitoring system would not replace the existing ones, but could provide real-time information to improve the mitigation strategies during severe nuclear accidents, and also for long-term monitoring.

\section{REFERENCES}

[1] INES, The International Nuclear and Radiological Event Scale, IAEA, 2008. [Online]. Available: https://wwwpub.iaea.org/MTCD/Publications/PDF/INES2013web.pdf

[2] C. Bataille and B. Sido, "Rapport de la mission parlementaire sur la sécurité nucléaire, la place de la filière et son avenir Rapport d'étape : la sécurité nucléaire", Office Parlementaire d'Évaluation des Choix Scientifiques et Technologiques
(OPECST), Report $n^{\circ} 701$, June 2011. [Online]. Available: http://www.senat.fr/rap/r10-701/r10-7011.pdf

[3] ANR, "Investissements d'Avenir, Recherche en Matière de Sûreté Nucléaire et Radioprotection (RSNR)," 2012. [Online]. Available: https://anr.fr/fileadmin/aap/2012/ANRAAP-RSNR-2012.pdf

[4] ASN, "Complementary Safety Assessments of the French Nuclear Power Plants (European "Stress Tests")", Dec. 2011. [Online]. Available: http://www.french-nuclearsafety.fr/content/download/53850/367799/version/1/file/12 0106-ASN-Report-CSA.pdf

[5] P. Ferdinand, L. Maurin, S. Rougeault, H. Makil, G. Cheymol, H. Maskrot, P. Le Tutour, D. Duval, Ch. Journeau, J.-F. Villard, J.-F. Haquet, Q. Souquet, L. Barbot, J. Miss, I. Duhamel, B. Dechenaux, M. Brovchenko, G. Musoyan, S. Balleydier, F. Pouillé, G. Helleux, S. Fourrez and L. Pichon, "DISCOMS: DIstributed Sensing for COrium Monitoring and Safety", in CANSMART 2015 Conf., Vancouver, Canada, 2015. [Online]. Available: https://hal-cea.archivesouvertes.fr/cea-02151741

[6] L. Barbot, J.-F. Villard, S. Fourrez, L. Pichon and H. Makil, "The Self-Powered Detector Simulation 'MATiSSe' Toolbox applied to SPNDs for severe accident monitoring in PWRs", in ANIMMA 2017 Conf., Liège, Belgium, 2017. [Online].

Available: https://doi.org/10.1051/epjconf/201817008001

[7] L. Pascucci-Cahen and P. Momal, "Massive radiological releases profoundly differ from controlled releases", Eurosafe forum, 2012. [Online]. Available: https://www.irsn.fr/FR/Actualites presse/Actualites/Docum ents/EN_Eurosafe-2012 Massive-releases-vs-controlledreleases_Cost IRSN-Momal.pdf

[8] M. Brovchenko, B. Dechenaux, K.W. Burn, P. Console Camprini, I. Duhamel and A. Peron, "Neutron-gamma flux and dose calculations in a Pressurized Water Reactor (PWR)", in ICRS-13 \& RPSD-2016 Conf., Paris, France, 2016. [Online]. Available: https://doi.org/10.1051/epjconf/201715305008

[9] M. Brovchenko, I. Duhamel and B. Dechenaux, "Neutrongamma flux and dose calculations for feasibility study of DISCOMS instrumentation in case of severe accident in a GEN 3 reactor", in ICRS-13 \& RPSD-2016 Conf., Paris, France, 2016. [Online]. Available: https://doi.org/10.1051/epjconf/201715307030

[10] G. Cheymol, L. Maurin, L. Remy, V. Arounassalame, H. Maskrot, S. Rougeault, V. Dauvois, P. Le Tutour, N. Huot, Y. Ouerdane and P. Ferdinand, "Tests under irradiation of optical fibers and cables devoted to remote corium monitoring in case of severe accident in a Nuclear Power Plant", in ANIMMA 2019 Conf., Portorož, Slovenia, 2019.

[11] Spécifications chimiques des produits et matériaux utilisables en centrale - PMUC, EDF standard, 2008.

[12] Tests for electric cables under fire conditions - Circuit integrity - Part 25: Procedures and requirements - Optical fibre cables, IEC standard 60331-25, 1994.

[13] D. Di Francesca, S. Girard, I. Planes, A. Cebollada, G. Li Vecchi, A. Alessi, I. Reghioua, C. Cangialosi, A. Ladaci, S. Rizzolo, V. Lecœuche, A. Boukenter, A. Champavère and Y. Ouerdane, "Radiation Hardened Architecture of a SingleEnded Raman-Based Distributed Temperature Sensor", IEEE Transactions on Nuclear Science, Vol. 64, No. 1, January 2017. [Online]. Available: https://dx.doi.org/10.1109/TNS.2016.2631539

[14] D. Alasia, A. Fernandez Fernandez, L. Abrardi, B. Brichard and L. Thévenaz, "The effects of gamma-radiation on the properties of Brillouin scattering in standard Ge-doped optical fibres", Measurement Science and Technology, Volume 17, Number 5, 7 April 2006. [Online]. Available: https://dx.doi.org/10.1088/0957-0233/17/5/S25

[15] T.R. Parker, M. Farhadiroushan, R. Feced, V.A. Handerek, and A.J. Rogers, "Simultaneous Distributed Measurement of Strain and Temperature from Noise-Initiated Brillouin Scattering in Optical Fibers", IEEE Journal of Quantum Electronics, Volume: 34, Issue: 4, Apr 1998. [Online]. Available: https://doi.org/10.1109/3.663443 